\title{
MODELING OF EMERGENCY EVACUATION IN BUILDING FIRE
}

\author{
H. Bayat ${ }^{1}$, M. R. Delavar, ${ }^{2, *}$ W. Barghi ${ }^{1}$, S.A. EslamiNezhad ${ }^{1}$, P. Hanachi ${ }^{3}$, and S. Zlatanova ${ }^{4}$ \\ ${ }^{1}$ Department of GIS, School of Surveying and Geospatial Eng., College of Engineering, University of Tehran, Tehran, Iran \\ (hadibayat, Wrya.Barghi, ahmad.eslami73@ut.ac.ir) \\ ${ }^{2}$ Center of Excellence in Geomatic Eng. in Disaster Management, School of Surveying and Geospatial Eng., College of \\ Engineering, University of Tehran, Tehran, Iran, mdelavar@ut.ac.ir \\ ${ }^{3}$ School of Urban Planning, College of Fine Arts, University of Tehran, Tehran, Iran, pirouzhanachi@ut.ac.ir \\ ${ }^{4}$ GRIS, Faculty of Built Environment, UNSW Sydney, Australia, s.zlatanova@unsw.edu.au
}

\section{Commission IV, WG IV/5}

KEY WORDS: Building Information Modelling, Indoor Path finding, 3D Modelling, GIS

\begin{abstract}
:
One of the main problems of rescue workers in confrontation of fired complex buildings is the lack of sufficient information about the building indoor environment and their emergency exit ways. Building information modeling (BIM) is a database for building a 3D model of building information to create a 3D building geometry network model. This paper has implemented some GIS and BIM integration analyses to determine the shortest and safest paths to people under fire risk and simulate their movement in the building. Plasco building was a multi-story shop in Tehran which has been fired in 2017 and destroyed. This paper attempts to simulate the firefighting and rescue operations in Plasco Building using an integration of BIM and GIS. There is no detailed information about the building and the fire incident, therefore the developed BIM and corresponding geometric network might differ slightly. The shortest and safest paths to the exit door or windows where the fire ladders are located are computed and analyzed. As a result of 15 scenarios developed in this paper, it was found that at $87 \%$ of the cases, the safest paths for the emergency exit of the people at risk were longer than the shortest paths. This study has evaluated different scenarios for the shortest and safest paths using Dijkstra algorithm considering different origins and destination points in the 3D indoor environment to assist the rescue operations.
\end{abstract}

\section{INTRODUCTION}

People usually spend more time in their daily life in indoor building environments such as home, office and shopping centers than outdoors. In addition, increasing the complexity of buildings is making urban crisis management more complex. According to reports and statistics from the National Fire Protection Association (NFPA, 2012), in the past few years, fires in the United States have killed and injured many people and firefighters and left billions of dollars in damage. Recent research related to the routing and emergency discharge of individuals inside the burning building verified that the quality of estimation of damage is highly dependent on the network model which requires complete indoor information, usually obtained from architectural, engineering and construction (AEC) management applications, which can be applied to Building Information Modeling (BIM) throughout the building life cycle (Cerovsek, 2011; Volk et al., 2014). In addition, BIM is applicable to better understand the building environment and can be very effective to extract an internal path network. BIM is a three-dimensional modeling of the geometry and building components that it is implemented on different software platforms. BIM does not completely include the location properties and analyses associated with the building (Liu et al., 2017).

Geospatial information systems (GIS) provide the spatiotemporal capabilities which can be integrated with BIM to support search and rescue operations (Kang and Hong, 2015; Bansal and Pal, 2007). By geo-referencing BIM models, the location of each entity can be identified, making it possible to perform spatial analyses at different perspectives and levels of detail (Diakite and Zlatanova, 2020). BIM offers more intelligence and interoperability compared to traditional 3D CAD models (Rajabifard et al., 2019). On the other hand, BIM has a construction-based perspective for modeling 3D urban features (Diakite and Zlatanova, 2020).

Past research suggests adding and integrating GIS capabilities with BIM to enhance the efficiency and integrity of the systems which is proven to be effective in analyzing static and dynamic variables in indoor as well as outdoor environments (Claes and Holvoet, 2011). While GIS is mostly used in open spaces and $3 \mathrm{D}$ indoor, it allows for disaster management planning (Cao and $\mathrm{Lu}, 2012$ ). Therefore, using BIM and GIS can assist decision makers for search and rescue operations in both indoor and outdoor environments. The purpose of this study is to investigate a 3D network analysis using data obtained from the BIM of Plasco's Building which was burned in 2017, considering different scenarios, safe discharge parameters and shortest exit routes.

\section{LITERATURE REVIEW}

\subsection{Building Information Modeling (BIM)}

Building information modeling (BIM) is based on computeraided design (CAD) technologies introduced in the late 1970s (Sun et al., 2017). This technology was first used in the project design phase and rapidly became commonplace in the executive

\footnotetext{
Corresponding author
} 
and operational phases. After decades of introducing this technology, it seems that there is no unified definition of BIM, yet. The US National Modeling Standard cycle (NBIMS, 2007) defines the building information model as a digital characterization in a physical and functional description of the structure, which is a source of knowledge sharing for the structure and the basis of trust for decision making throughout its life. It is more of a database than a graphical model. Eastman et al. (2011) define BIM as a new modelling technology and a set of processes for generating, communicating and analysing building models.

BIM models are strong in providing accurate building information at a construction scale. This allows us to feed a wide range of applications among witch indoor navigation (Diakite and Zlatanova, 2018; Isikdag et al., 2013).BIM models might not be available for old buildings, but they can be created with laser scanning technology. For example, Nikoohemat et al. (2020) present a dedicated procedure for 3D indoor modelling, which focusses on reconstruction of spaces, door and windows, i.e. objects of critical importance for emergency response. The integration of BIM and GIS information in the last decade is considered a great attention (Dollner and Hagedorn, 2007). With the integration of BIM and GIS, it became rapidly clear that merging both would be useful for performing spatial analyzes e.g. for emergency operation management (Boguslawski et al., 2015; Tashakkori et al., 2015).

\subsection{Emergency Routing}

Most of the research on indoor emergency evacuation are concentrated on finding the direction and navigation to the exit doors in the building (Kwan and Lee, 2005; Lee, 2007; Liu and Zlatanova, 2012; Vanclooster et al., 2013). Previous research has addressed various aspects of discharge, including low-risk routes (Vanclooster et al., 2013), evacuation monitoring (Alattas et al., 2020), route simplicity (Duckham and Kulik, 2003), improved navigation network (Kwan and Lee, 2005; Lee, 2007) and even models for seamless indoor-outdoor navigation (Yan et al., 2019; Zlatanova et al. 2020).

Tashakkori et al. (2015) developed the building indoor space model, based on the Industry Foundation Classes (IFC) standard with environmental information from GIS databases to enhance decision makers' information on indoor space to optimize the time of emergency relief operations.

\subsection{Network Analysis}

3D Network Analysis can be used to find the shortest path in the indoor environments of the buildings for disaster management (Cao and $\mathrm{Lu}, 2012$ ). A 3D network model is based on nodes and edges where nodes represent building units (in this paper shops and building rooms) and edges represent the path of communication between the two nodes, so that people between the nodes can move from the edges to the ends. Such networks can be automatically derived from BIM models (Isikdag et al., 2013). The network can be derived from geometric building representations (2D or 3D) using different approaches, but the commonly accepted methods include spacebased (placing nodes in the centers of the spaces, such as rooms and corridors), medial axis transform (creating nodes at critical points in the skeleton of the building) or visibility (placing nodes at the doors). It is possible to minimize a parameter (time, distance, safety) of this model that makes it useful for emergency response and evacuation (Xiong et al., 2017).

\section{DATA AND METHODOLOGY}

\subsection{Case Study}

Plasco building was a 16-story shopping building built in 1963 as the highest building in Tehran. On 19 January 2017, the building went in fire. The fire spread on the tenth floor and several local failures took place, eventually after three and a half hours of starting the fire, Plasco building collapsed (Plasco Building Report, 2017).

The purpose of selecting this building as a case study is to highlight the importance of this incident which left more than 16 deaths most of them were fire fighters. As the building has totally collapsed, Tehran municipality Plasco data before and after the fire incident were used to simulate the emergency evacuation in the building. The location of Plasco building is shown in Figure 1. The flowchart of the proposed methodology is illustrated in Figure 2.

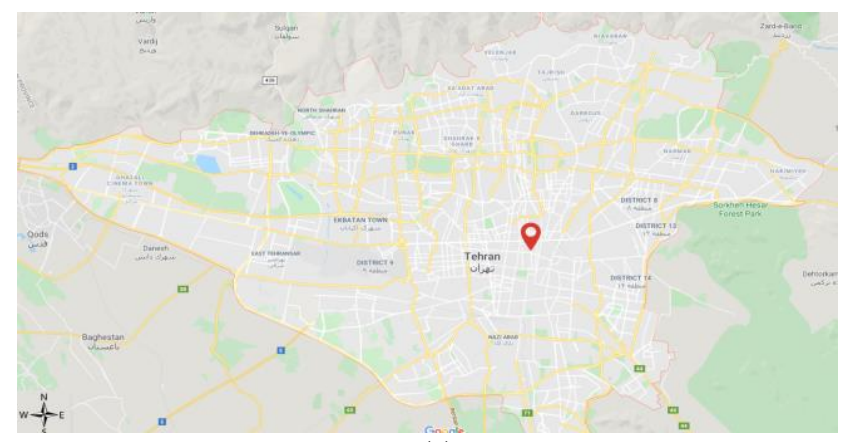

(a)

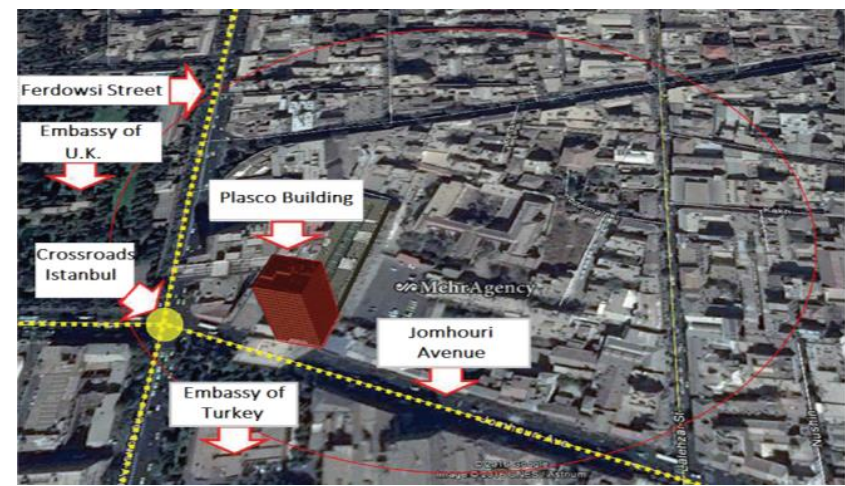

(b)

Figure 1. The Location of Plasco building

(a) Tehran (b) Plasco building

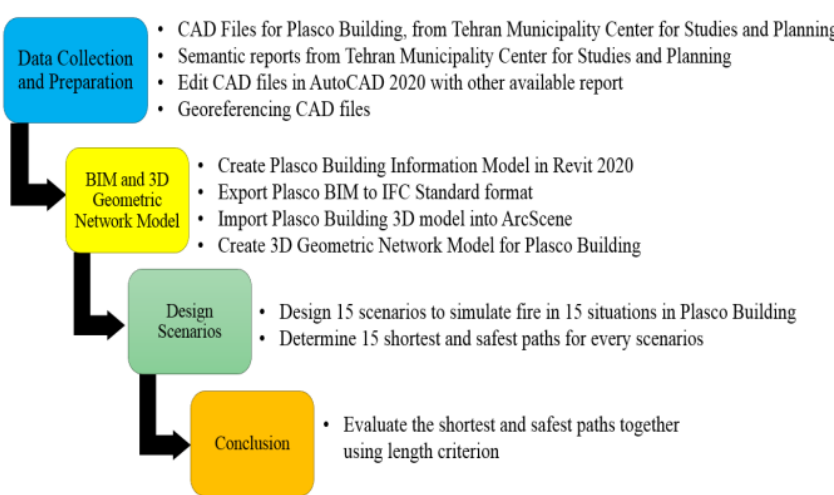

Figure 2. The flowchart of the proposed method 


\subsection{Building Information Modeling and Creation of the 3D Geometric Network Model}

In this research, at first, the data related to Plasco building, such as maps, images, and information on shops were collected. Then, each floor plan was mapped in the CAD format and imported to the Revit software to model the building information. Revit is an architectural software from the Autodesk Company that has some features to be used in BIM. After the building information modelling step, we need to prepare it for entry into the GIS environment. The output model can be in IFC format which is an international standard for building information modelling (Building Smart, 2008). After building the model, the IFC file has been converted using FME software and imported in ESRI ArcGIS. In the GIS environment, a geodatabase is created and a separate layer is formed for each building component (e.g. doors, windows, ceilings, and walls).

To simulate the indoor search and rescue teams' movements, a model of the indoor building network has been constructed. Then a three-dimensional network of the indoor building paths has been created. Figure 3.a shows the topology or logical network and Figure 3.b illustrates the geometric network. These representations assist using the routing algorithms in graphs such as Dijkstra to find the shortest and safest paths.

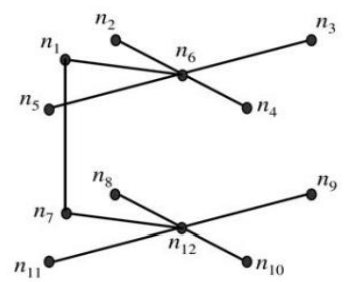

(a)

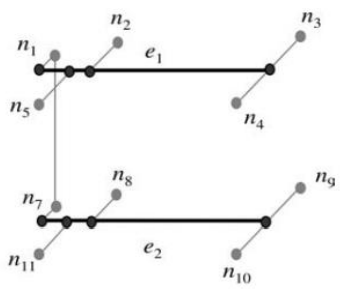

(b)
Figure 3. The modelling of indoor building path network (a) topologic model (b) geometric network model (Lee, 2001).

\subsection{Dijkstra Algorithm}

Routing algorithms can be used to determine the best or the least cost route between two or more points which can be a distance or other parameters to be used as weight. Dijkstra algorithm is used in this research for routing in graphs. In this algorithm, a label is assigned to each graph equal to the shortest distance from that node to the source node. The algorithmic process is completed when all the nodes are completed (Singal and Chhillar, 2014). Of the unselected nodes, the least cost node is selected as the next node. Here the shortest path is the path with the least length (low weight means short length). The safest path means the path in which the flammability of the material is the minimum (the weight of each edge is its flammability).

In fact, the shortest path is the path that has the lowest cost. In this study, the cost for short paths is the distance traveled, while in safe routing, the goal is to find the route to be safe for people. Since the fire situation is investigated and the location of the fire is not accurate, we selected the flammability of materials contained in each floor as a measure of the safety of the path and applied it to the three-dimensional network of the building. Because of the spread of fire, it is obvious that high flammable materials are first exposed to fire. For example, in Figure 4, the path $A$ to $B$ is selected, then $E$ and $F$, and the optimal path is indicated in green (A-B-E-F).

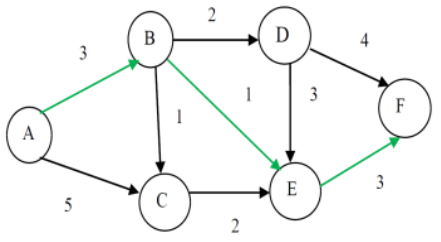

Figure 4. Example for the shortest path (Singal and Chhillar, 2014).

\subsection{Safe Routing Rules}

According to the Plasco incident report (Plasco Building Report, 2017), one of the most important factors in this fire and its spread was the flammability of the indoor materials. Here, the flammability parameter (the tendency of the material to react with oxygen) is used as a criterion for checking the safety of the route. Since Plasco building is not currently available, based on the available reports, the edges and nodes of the network are weighted.

\subsection{Emergency Evacuation Scenario}

In this research, several scenarios have been simulated based on available information and our assumptions. In some of our scenarios, we assume the exit is through the window of the units where the fire ladder is located. In a few other scenarios, we consider exit ways through the main door. The origins and destinations for the search and rescue operations are selected to have a good distribution of possible routes for the operations.

\subsection{Designing a Network Analysis Model}

To perform the network analysis, an indoor track threedimensional network model was created. Then the flammability criterion as the weight was applied using Model Builder and ArcGIS Network Analysis tools.

\section{IMPLEMENTATION}

\subsection{Draw Floors Plan and Create a BIM}

In this study, we selected Plasco Building as a case study and collect its data (e.g. old maps, images, technical and legal reports, and expert opinions). According to Figure 5, we modified the floor plan in AutoCAD 2020 software. The main input data for this study were the primary code maps that we modified using existing technical reports and images provided by the Tehran Municipality Centre for Studies and Planning and then according to the building dimensions, the as built map of the building was produced (Figure 5).

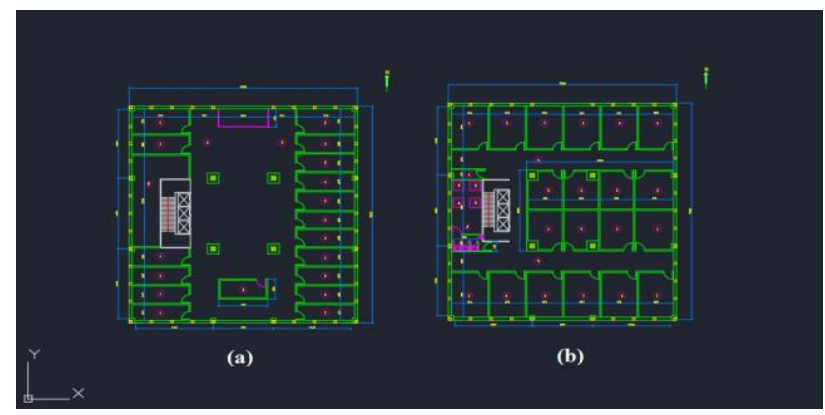

Figure 5. Drawing of Plasco building floors plan and its modification according to the available technical reports (a) $2^{\text {nd }}$ floor (b) $4^{\text {th }}$ floor to the $14^{\text {th }}$ floor 
Then according to Figure 6, we have created the building information model in Autodesk's Revit 2020 software.

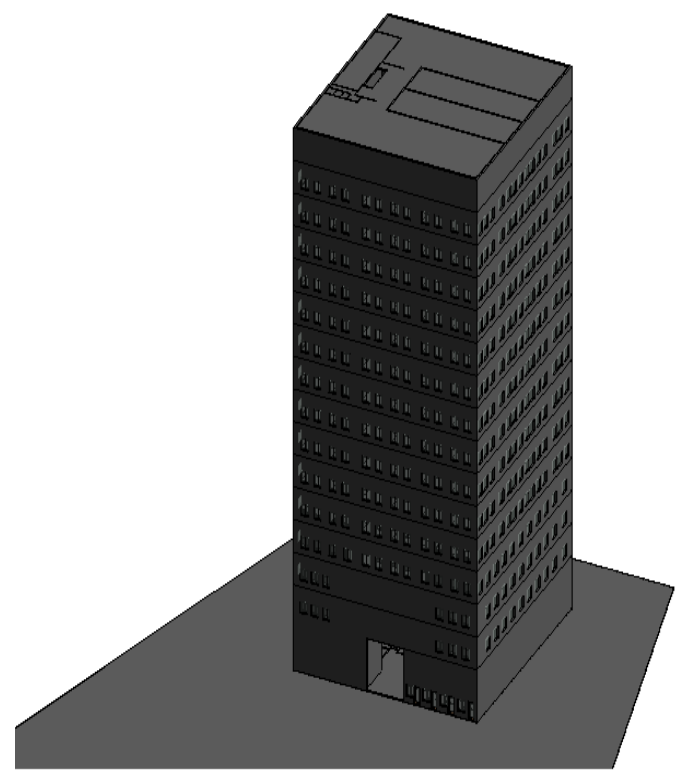

Figure 6. Plasco Building Information Model in Revit 2020

\subsection{Creating a 3D Building Network}

We needed a geometric network to perform the indoor routing analysis. The most important purpose of creating this network in this research is to determine the shortest and safest paths. The output of the BIM imported to the GIS environment. In this geometric network model (GNM), a node to each building unit (such as room) is assigned and the nodes (including hallways and stairs) are connected using the edges. Figure 7, illustrates the 3D model of Plasco's building in the GIS environment.

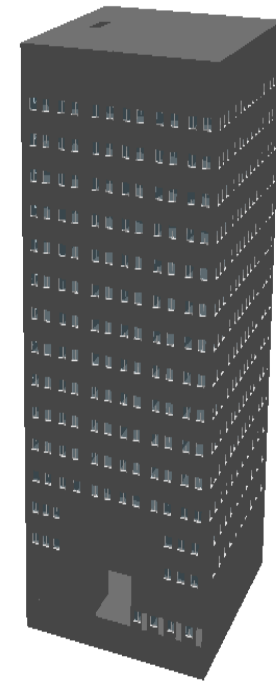

(a)

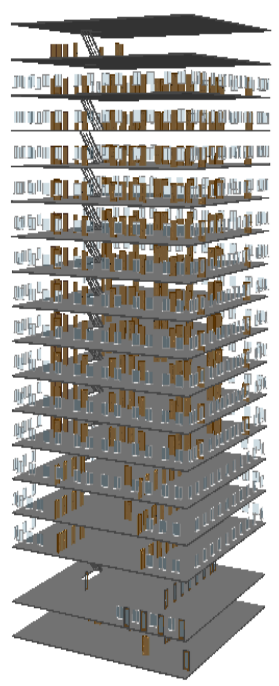

(b)
Figure 7. 3D model of Plasco building in the GIS environment (a) Layers of walls and structure (b) Layers of doors, windows and stairs

The 3D geometric network of Plasco building path is shown in Figure 8 (Our network had 595 nodes and 612 edges).

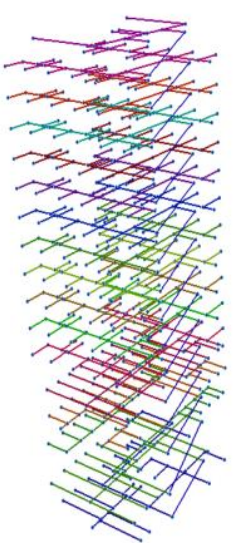

(a)

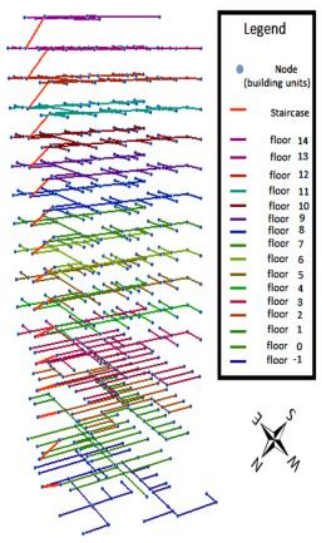

(b)
Figure 8. 3D model of Plasco building (a) southern view (b) northern view

The combination of the 3-dimensional geometrical network of Plasco building path and 3D model of Plasco building are shown in Figure 9.

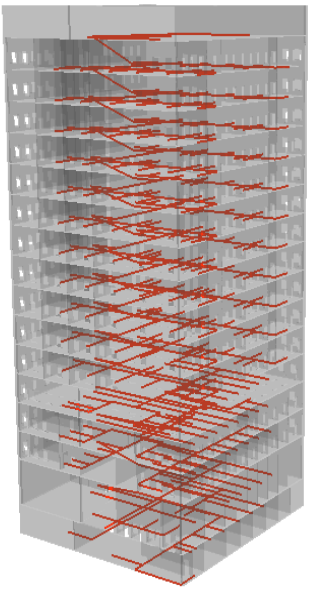

Figure 9. Plasco building path network and model

\subsection{Network Analysis}

We analysed the network using existing tools such as ArcGIS Network Analysis for two situations to find the shortest path and the safest path. Only the distance criterion was evaluated to find the shortest path to reach the destination and to find the safest path as well. The flammability parameter of the material was determined by considering the information available from Plasco building and applying it as a weight on the network to find the optimal path (the least flammable weight of the material) to the destination. According to the experts' opinion, we applied some materials such as wood, fabric, and nylon as the flammability parameters for the shops that had such materials in their store (which was approximately estimated according to the data collected from the building considering the minimum value as 1 and the maximum value as 99).

\section{RESULTS}

In this section, we discuss three out of the 15 scenarios implemented and analysed on the shortest and safest paths. Finally, the results of the 15 scenarios are compared based on the shortest and safest paths as shown in 
Table 1. The difference among these scenarios is at their starting points.

\begin{tabular}{|c|c|}
\hline $\begin{array}{c}\text { Scenario } \\
\text { No. }\end{array}$ & Start point \\
\hline 1 & South side room at the second floor \\
\hline 2 & End room of the west of the first floor \\
\hline 3 & The $9^{\text {th }}$ floor left room \\
\hline 4 & Left room, end of the $3^{\text {rd }}$ floor hall \\
\hline 5 & The first room on the $4^{\text {th }}$ floor \\
\hline 6 & The $8^{\text {th }}$ floor corridor end \\
\hline 7 & The $8^{\text {th }}$ floor corridor \\
\hline 8 & Room on the east side of the $5^{\text {th }}$ floor \\
\hline 9 & One of the rooms on the west side of the $10^{\text {th }}$ \\
\hline 10 & floor \\
\hline 11 & The $1^{\text {st }}$ floor corridor end room \\
\hline 12 & Side room staircase at floor 4 \\
\hline 13 & $\begin{array}{c}\text { Elementary room } \text { the east side of the } 6^{\text {th }} \text { floor } \\
\text { the } 14^{\text {th }} \text { floor } \text { on the west side of }\end{array}$ \\
\hline 14 & End of the $13^{\text {th }}$ floor corridor \\
\hline 15 & The $12^{\text {th }}$ floor staircase \\
\hline
\end{tabular}

Table 1. Descriptions of the 15 scenarios

In this paper, it has been decided to address only three scenarios. The reason for choosing these three scenarios is based on the difference between their safest and shortest paths. We chose scenario No. 1 because, in this mode, the safest path is equal to the shortest path, scenario No. 11, because the difference between the safest path and the shortest path is the largest. Also, because of the more similarity of scenarios to scenario No. 5 , we chose this scenario.

\subsection{Scenario No. 1}

The fire is spreading on the upper floors and a person is in the end room of the second floor on the southern side of the building and does not know the location of the fire, It is reported by phone that the fire did not spread to the lower floors and two shortest and safest routes were obtained for this person. According to the position of the ladders in the windows on the northern side of Plasco building, in this scenario, both lengths of the shortest and the safest paths are the same. The length of the route is 107.9 meters. The result of scenario No. 1 is shown in Figure 10.

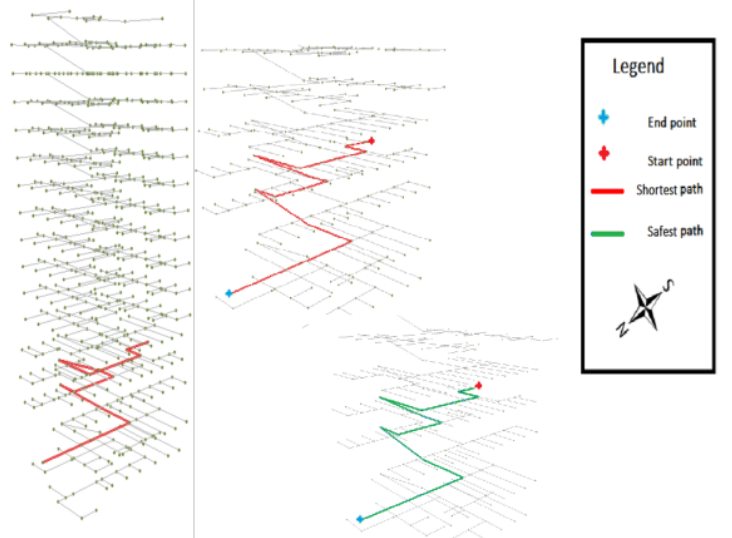

Figure 10. Scenario No. 1 representing the shortest and safest paths

\subsection{Scenario No. 5}

In the fifth scenario, the person is on the northern side of the fourth floor of the building and the fire is spreading from the southern side of the same floor. In this scenario, as shown in Figure 11, there is little difference between the safest and shortest paths as there are many obstacles for this scenario including fire, fabric materials inside the units, as well as blocking the main door path. The length of the shortest path was 133.1 meters and that of the safest path was 141.8 meters. According to Figure 11, red is the shortest path and green is the safest path.
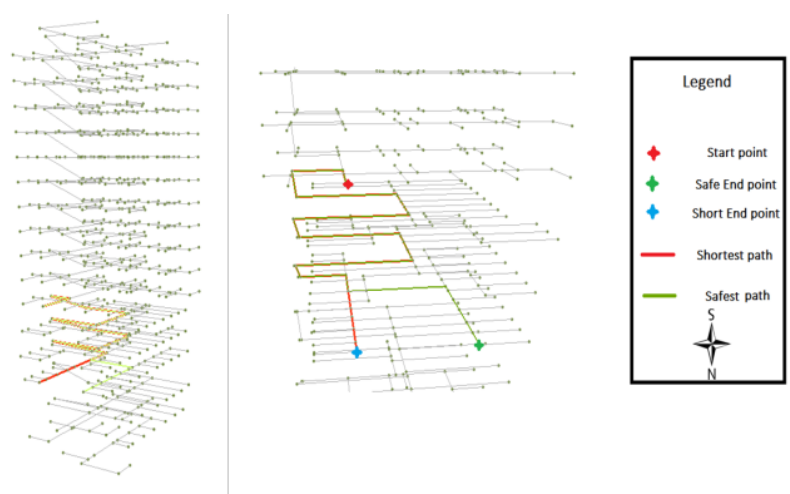

Figure 11. Scenario No. 5- The shortest and safest paths

\subsection{Scenario No. 11}

In this scenario, it is assumed that the way out of the main door is available and the person intends to leave the room on the fourth floor above the ground floor. A fire is raging on the upper floors and fire ladders have been erected on the upper floor. The result was that exit from the main door was selected as the safest path and exit through fire ladders was considered as the shortest path. The length of the shortest path was 64.7 meters and that of the safest path was 175.3 meters. The result of scenario No. 11 is presented in Figure 12 where the red is the safest path and green is the shortest path.
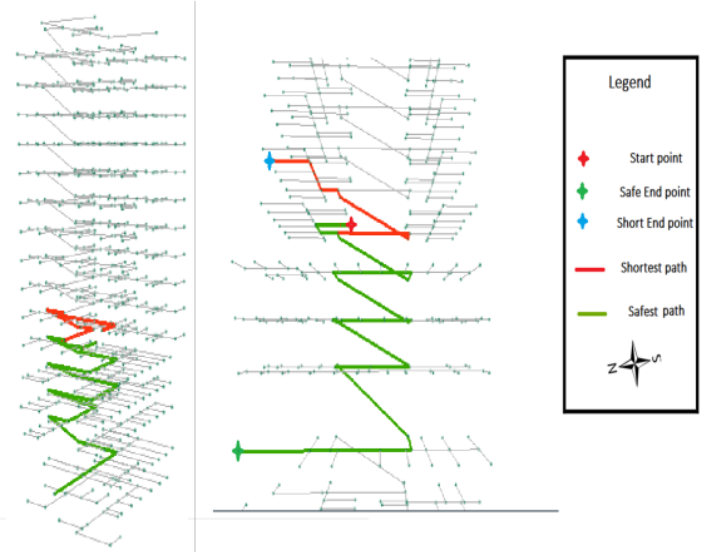

Figure 12. Scenario No. 11-Shortest and safest paths

\section{CONCLUSION}

In this study, the BIM of Plasco building was created to determine the shortest and safest path in an emergency exit at 
the fire time to make a comprehensive assessment. We analysed the network using network analysis tools. Using the flammability parameter of the materials in the building units, we performed the shortest and safest paths in the 15 scenarios where 3 scenarios were mentioned here. In $13 \%$ of the scenarios, the shortest and safest paths were equal (scenarios No. 1 and 7) and in $87 \%$ of the scenarios, the safest paths were longer than the shortest paths.

According to Figure 13, there are obstacles that make the shortest paths not recognized as the safest paths (in this study only the flammability of the material was considered as an obstacle), so it is better to have a pre-crisis planning for highrise and complex buildings to remove obstacles from the possible shortest paths so that the shortest paths become the safest paths.

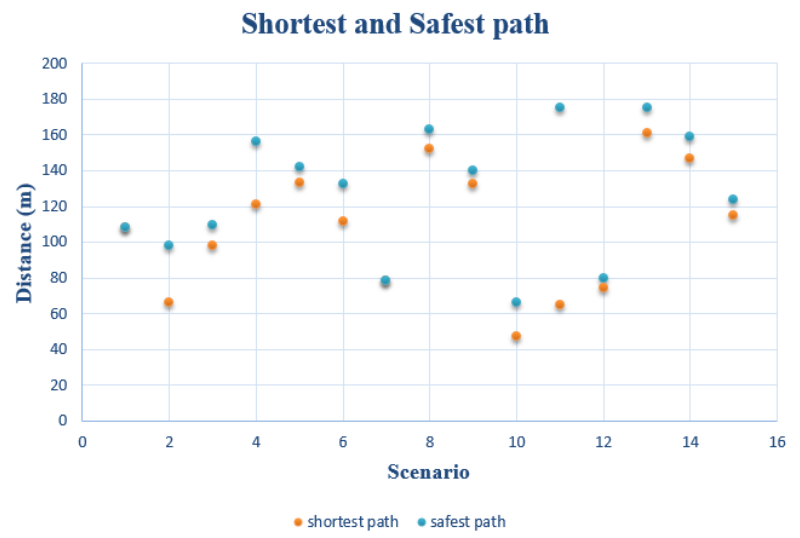

Figure 13. Scenarios of the safest and shortest paths

In these cases, the proposed integrated BIM and GIS approach can significantly assist for the rescue operations. In the implemented scenarios, due to the scattering of flammable materials such as clothes and fabrics in the corridors of the floors and inside the units and the narrowness of the corridors, the shortest path and safest path were considered during the fire crisis inside the building. Because the flammability of materials is important here, these results can be used to maintain similar buildings so that high-flammability materials are not placed on emergency paths. One of the most important outcomes of this study is that different scenarios can be presented as the safe emergency exit paths at the time of the disasters. For future research, it is suggested that in addition to considering the material flammability criterion, other criteria such as route obstacles and blockages can be considered. Since finding the safest path (low-flammability path) is considered as a routing algorithm by applying the flammability weight of the material, it is obvious that the safe paths may not be the shortest path. The best-case scenario is that the shortest path found has the lowest weight of flammability to be considered as the safest path, too. It can also be concluded that combination of different technologies may serve better emergency response.

\section{REFERENCES}

Alattas, A., Van Oosterom, P., Zlatanova, S., Hoeneveld, D. and Verbree, E., 2020, LADM-IndoorGML for exploring user movements in evacuation exercise, Land Use Policy, in Press, doi.org/10.1016/j.landusepol.2019.104219
Bansal, V.K. and Pal, M., 2007. Potential of geographic information systems in building cost estimation and visualization. Automation in Construction, 16(3), 311-322.

Boguslawski, P., Mahdjoubi, L., Zverovich, V., Fadli, F. and Barki, H., 2015. BIM-GIS modelling in support of emergency response applications. Building Information Modelling (BIM) in Design, Construction and Operations, Bristol, UK, 149, p.381.

Building Smart, 2008. http://www.buildingsmarttech.org/specifications.

Cerovsek, T., 2011. A review and outlook for a 'Building Information Model' (BIM): A multi-standpoint framework for technological development. Advanced engineering informatics, 25(2), 224-244.

Claes, R. and Holvoet, T., 2011. Ant colony optimization applied to route planning using link travel time predictions. In 2011 IEEE International Symposium on Parallel and Distributed Processing Workshops and PhD Forum (pp. 358365). IEEE.

Diakité, A.A. and Zlatanova, S., 2018. Spatial subdivision of complex indoor environments for 3D indoor navigation. International Journal of Geographical Information Science, 32(2), 213-235.

Diakite, A.A. and Zlatanova, S., 2020. Automatic georeferencing of BIM in GIS environments using building footprints. Computers, Environment and Urban Systems, 80, p. 101453

Dollner, J., Hagedorn, B., 2007. Integrating urban GIS, CAD, and BIM data by service based virtual 3D city models. Urban and Regional Data Management-Annual, 157-160.

Duckham, M., Kulik, L., 2003. "Simplest" Paths: Automated Route Selection for Navigation, Spatial Information Theory, Foundations of Geographic Information Science, ed. W. Kuhn, M. Worboys \& S. Timpf, Editors, Springer Berlin Heidelberg, 169-185.

Eastman, C.M., Eastman, C., Teicholz, P., Sacks, R. and Liston, K., 2011. BIM handbook: A guide to building information modeling for owners, managers, designers, engineers and contractors. John Wiley \& Sons.

Isikdag, U., Zlatanova, S. and Underwood, J. 2013, A BIMOriented Model for supporting indoor navigation requirements, Computers, Environment and Urban Systems, Volume 4 September 2013, pp. 112-123

Kang, T.W. and Hong, C.H., 2015. A study on software architecture for effective BIM/GIS-based facility management data integration. Automation in construction, 54, 25-38.

Kwan, M.P., Lee, J., 2005. Emergency response after 9/11: the potential of real time 3D GIS for quick emergency response in micro-spatial environments. Computers, Environment and Urban Systems, 29, 93-113.

Lee, J., 2001. 3D data model for representing topological relations of urban features. In Proceedings of the 21st annual ESRI international user conference, San Diego, CA, USA. 
Lee, J., 2007. A Three-Dimensional Navigable Data Model to Support Emergency Response in Microspatial BuiltEnvironments. Annals of the Association of American Geographers, 97(3), 512-529.

Liu, L., Zlatanova, S., 2012. Towards a 3D network model for indoor navigation, Urban and Regional Data Management, ed. Zlatanova, Ledoux, Fendel \& Rumor, CRC Press, Taylor and Francis Group: London, 79-92.

Liu, X., Wang, X., Wright, G., Cheng, J.C., Li, X. and Liu, R., 2017. A state-of-the-art review on the integration of Building Information Modeling (BIM) and Geographic Information System (GIS). ISPRS International Journal of GeoInformation, 6(2), p.53.

Lu, F. and Cao, Y., 2012. Three-Dimensional Modeling for Buildings Evacuation Management.

National BIM Standard $\quad 2007$. National Building Information Modelling Standards: Overview. United States: National Institute of Building Science.

Nikoohemat, S., Diakité, A.A., Zlatanova, S. and Vosselman, G, 2020 Indoor 3D reconstruction from point clouds for optimal routing in complex buildings to support disaster management, Automation in Construction, Volume 113, May 2020, 103109

NFPA, National Fire Protection Association, 2013. http:// www.nfpa.org/.

Plasco Building Management and Legal Technical Report, Tehran Municipality Center for Studies and Planning, 2017.

Rajabifard, A., Atazadeh, B. and Kalantari, M., 2019. BIM and Urban Land Administration. CRC Press.

Sikdag, U., Zlatanova, S. and Underwood, J., 2013. A BIMOriented Model for supporting indoor navigation requirements. Computers, Environment and Urban Systems, 41, 112-123.

Singal, P., Chhillar, R.S., 2014. Dijkstra Shortest Path Algorithm using Global Positioning System. International Journal of Computer Applications, 101(6), 12-18.

Sun, C., Jiang, S., Skibniewski, M.J., Man, Q. and Shen, L., 2017. A literature review of the factors limiting the application of BIM in the construction industry. Technological and Economic Development of Economy, 23(5), 764-779.

Tashakkori, H., Rajabifard, A., Kalantari, M., 2015. A new 3D indoor/outdoor spatial model for indoor emergency response facilitation. Building and Environment, 89, 170-182.

Vanclooster, A., De Maeyer, Ph., Fack, V., and Van de Weghe, N., 2013. Calculation least risk paths in 3D indoor space, Int. Arch. Photogramm. Remote Sens. Spatial Inf. Sci., XL-2/W2, 113-120, https://doi.org/10.5194/isprsarchives-XL-2-W2-1132013, 2013.

Volk, R., Stengel, J. and Schultmann, F., 2014. Building Information Modeling (BIM) for existing buildings-Literature review and future needs. Automation in construction, 38, 109127.
Xiong, Q., Zhu, Q., Du, Z., Zhu, X., Zhang, Y., Niu, L., Li, Y. and Zhou, Y., 2017. A dynamic indoor field model for emergency evacuation simulation. ISPRS International Journal of Geo-Information, 6(4), p.104

Yan, J., Diakité A.A. and Zlatanova, S., 2019, A generic space definition framework to support seamless indoor/outdoor navigation systems, Transactions in GIS, 23: 1273-1295

Zlatanova, S., Yan, J., Wang, Y. Diakité, A.A., Isikdag, U., Sithole, G. and Barton, J., 2020, Spaces in Spatial Science and Urban Applications-State of the Art Review, ISPRS Int. J. Geo-Inf. 2020, 9(1), 58; 